This is a postprint version of the following published document:

Bertolia,S., Brückerb, H. and Fernández-Huertas, J (2016). The European crisis and migration to Germany. Regional Science and Urban Economics, v. 60, pp. 61-72. Available in: https:// doi.org/10.1016/j.regsciurbeco.2016.06.012

(C) Elsevier

\title{
(c) ()응
}

This work is licensed under a Creative Commons Attribution-NonCommercialNoDerivatives 4.0 International License. 


\title{
The European crisis and migration to Germany ${ }^{\text {ts }}$
}

\author{
Simone Bertoli ${ }^{\mathrm{a}, *, 1}$, Herbert Brücker ${ }^{\mathrm{b}, 2}$, Jesús Fernández-Huertas Moraga ${ }^{c, 3}$ \\ ${ }^{a}$ CERDI, University of Auvergne and CNRS, France \\ ${ }^{\mathrm{b}} \mathrm{IAB}$ and University of Bamberg, Germany \\ 'Universidad Carlos III de Madrid, Spain
}

\section{A B S T R A C T}

The size of migration flows to Germany from other European countries surged in the aftermath of the 2010 European crisis, and this paper explores the main determinants of this large increase. International migrants tend to move more than once in their lives, and migration episodes to Germany make no exception in this respect. This paper explores some relevant implications of this simple observation for the estimation of gravity models, which is done here with bilateral monthly migration data. We demonstrate that ignoring the sequential nature of migration decisions gives rise to multilateral resistance to migration, thus substan-tially biasing the estimates. We also show that the expectations about future economic conditions at origin significantly influence bilateral migration flows to Germany.

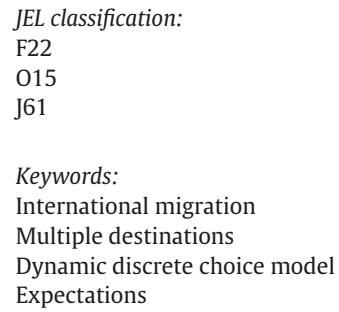

\section{Introduction}

Germany has been receiving large and growing gross migration flows from other countries in the European Union in recent years,

\footnotetext{
The authors are grateful to the Editor Giovanni Peri and to an anonymous referee for their useful comments and suggestions, and to Erhan Artuç, Frédéric Docquier Amparo González, Çağlar Özden, Enzo Weber and the participants at various conferences and seminars; the authors also thank Charlène Hacquebert and Josef Pschorn for their excellent work of data collection, and Alexander Berg, Stefanie Katz, Gunther Müller and Anja Wunder, who provided careful research assistance. Financial support from NORFACE research program on Migration in Europe - Social Economic, Cultural and Policy Dynamics is gratefully acknowledged; Simone Bertoli and Jesús FernándezHuertas Moraga are also grateful for the prize they received from the Asociación Libre de Economía; Simone Bertoli acknowledges the support received from the FERDI and the Agence Nationale de la Recherche of the French government through the program "Investissements d'avenir" (ANR-10-LABX-14-01); Jesús Fernández-Huertas Moraga received financial support from the Ministerio de Economía y Competitividad (Spain), grant MDM 2014-0431, and Comunidad de Madrid, MadEco-CM (S2015/HUM-3444). The usual disclaimers apply.

* Corresponding author.

E-mail addresses: simone.bertoli@udamail.fr (S. Bertoli), herbert.bruecker@iab.de (H. Brücker), jesferna@eco.uc3m.es (J. Fernández-Huertas Moraga).

1 CERDI, Bd. François Mitterrand, 65, F-63000, Clermont-Ferrand.

2 IAB, Weddigenstr. 20-22, D-90478, Nuremberg.

3 Madrid, 126, E-28903, Getafe (Madrid).
}

totaling at around 4.4 million between January 2006 and September $2014,{ }^{4}$ and contributing to make it the second largest migrant destination in the OECD by the end of this period (OECD, 2014). While such a surge is certainly related to the Eastern enlargement of the EU and to the economic crisis that has hit several European countries, a credible identification of the role played by institutional and economic factors has to be based on a suitable representation of the location-decision problem that would-be migrants face. Bertoli and Fernández-Huertas Moraga (2013) have shown that the estimation of gravity equations that are based on a random utility model with distributional assumptions à la McFadden (1974) produces biased estimates if location-specific utility is imperfectly modeled. A specific reason why this could occur is connected to the fact that migrants can move more than once throughout their lives. As Dustmann and Görlach (2015) observe, "permanent migrations are - and possibly always have been - the exception rather than the rule" (p. 491), and indeed the outflow of EU immigrants from Germany between January 2006 and September 2014 stood at around 3.1 million (Statistisches Bundesamt, 2015), in line with the observation that "gross migration in one direction [is] the best single

\footnotetext{
4 The bilateral migration figures are derived from a special data provision by the Federal Statistical Office (Statistisches Bundesamt, 2015).
} 
indicator of the amount of backflow" (Sjaastad, 1962, p. 81)..$^{5}$ This, in turn, implies that the attractiveness of a country at one point in time also depends not just on the expectations about its own future economic conditions, but also on the value associated to possible further moves, provided that migrants do not take myopic decisions. This sequential nature of migration decisions is typically disregarded when lying the theoretical basis of gravity models to be estimated on aggregate data.

We derive the specification that we bring to the data from a dynamic discrete choice model to describe the location-decision problem that individuals face at each point in time, building upon the model that Kennan and Walker (2011) employed to describe individual internal migration decisions. This derivation reveals that canonical specifications based on static micro-foundations with restrictive distributional assumptions produce biased estimates, as in Bertoli and Fernández-Huertas Moraga (2013), unless (i) current migration decisions are based on a myopic behavior or (ii) the world is frictionless, i.e., there are no migration costs.

The gravity equation based on the proposed dynamic microfoundations presents a multi-factor error structure (Bai, 2009, Pesaran, 2006), which informs the choice of the estimation approach that we adopt, characterized by being less data-demanding than the ones proposed by Artuç et al. (2010) and Arcidiacono and Miller (2011).

The estimation of the gravity equation with monthly bilateral migration data reveals that the movements in the unemployment rate and the migration policy changes that were introduced over our sample period exert a significant influence on the size of the bilateral migration flows to Germany. Concretely, a 10\% increase in the unemployment rate at origin is associated with a $5.4 \%$ increase in the bilateral migration rate, while the EU accession and the end of the seven-year transitional arrangements adopted by Germany towards new EU members states are estimated to increase the bilateral migration rate by $183 \%$ and $36 \%$ respectively. The estimates that we obtain with a canonical static micro-foundation, i.e., a static RUM model with i.i.d EVT-1 disturbances, are significantly biased, and the direction of the bias in the various coefficients is in line with the ones due to multilateral resistance to migration (Bertoli and Fernández-Huertas Moraga, 2013) and by the prevailing pattern of correlation in the data: the unemployment rate estimates are upward biased while the policy effects estimates are downward biased.

We also attempt to directly control for the confounding effect due to changing expectations about the future economic conditions at origin through two proxies, namely a synthetic measure of consumers' confidence and the yields on 10-year sovereign bonds on the secondary market. These two proxies, which we introduce for the first time in the migration literature, significantly influence bilateral migration flows to Germany in the expected direction, but their inclusion is per se insufficient to remove the bias on the coefficients of the other variables in the canonical static specification. This negative result is in line with our dynamic discrete choice model, as the current bilateral migration rate depends in a complex and nonlinear way on the expectations about future economic conditions in all potential locations, and not in the origin country only.

This paper draws from three main strands of literature. First, the literature on the determinants of international migration flows

\footnotetext{
5 See also Bijwaard et al. (2014) and Bandiera et al. (2013) for evidence on the incidence of temporary migration in different geographical and historical contexts; Artuç and Özden (2014) provide evidence that a substantial share of migrants have been residing outside their country of birth just before moving to the United States, thus suggesting that return is not the only available option at the end of a temporary migration experience.
}

(Beine et al., 2011, 2013, 2016; Belot and Ederveen, 2012; Belot and Hatton, 2012; Bertoli et al., 2011; Clark et al., 2007; Grogger and Hanson, 2011; Lewer and den Berg, 2008; Mayda, 2010; Pedersen et al., 2008), and more specifically on the papers that have relaxed the distributional assumptions on the underlying RUM model (Bertoli and Fernández-Huertas Moraga, 2015; Bertoli et al., 2013; Ortega and Peri, 2013), and those that have analyzed the determinants of migration to Germany, mainly in the context of the Eastern enlargement of the EU (Boeri and Brücker, 2001; Brücker and Siliverstovs, 2006; Fertig, 2001; Flaig, 2001; Sinn et al., 2001; Vogler and Rotte, 2000). Second, the literature on static (de Palma and Kilani, 2007; McFadden, 1974, 1978; Small and Rosen, 1981) and dynamic discrete choice models (Arcidiacono and Miller, 2011; Artuç et al., 2010; Kennan and Walker, 2011; Pessino, 1991). Third, the literature on the estimation of linear models with a common factor structure in the error term (Bai, 2009; Pesaran, 2006; Pesaran and Tosetti; 2011).

The remainder of the paper is structured as follows: Section 2 presents a RUM model that describes the sequential locationdecision problem that potential migrants face. Section 3 introduces our sample and data sources, and it also provides the relevant descriptive statistics. Section 4 presents the results of our econometric analysis. Section 5 draws the main conclusions of the paper.

\section{A sequential model of migration}

We consider a set of infinitely lived agents, each of them denoted by $i$, located in country $j$ that have to choose their preferred location from a set of countries $D$, with $\# D=n$, in period $t$. The utility of opting for country $k$ at time $t$ is given by:

$U_{i j k t} \equiv w_{k t}-c_{j k}+\beta V_{t+1}(k)+\epsilon_{i k t}$

This depends on: (i) a deterministic instantaneous component $w_{k t}$, ii) a deterministic component $c_{j k}$ that describes the cost of moving from $j$ to $k,{ }^{6}$ (iii) the discounted value, with time discount factor $\beta<1$, of the expected utility $V_{t+1}(k)$ from optimally choosing the preferred location from time $t+1$ onwards conditional upon being in $k$ at time $t$, and on (iv) a stochastic individual and time-specific serially uncorrelated component $\epsilon_{i k t}$. The evolution of $w_{j t}$, for all $j \in D$, is non-stochastic, ${ }^{7}$ and known to the agents, who also know the $n \times n$ matrix $C$ of bilateral migration costs. We also assume that individual $i$ chooses her preferred location after having observed the realizations of the stochastic component of utility at time $t$ for all countries.

We can obtain an analytic expression for the continuation payoff $V_{t+1}(k)$ in Eq. (1) by specifying the distributional assumptions on the stochastic component of utility $\epsilon_{i k t}$. If we assume that the stochastic component of utility follows an i.i.d. EVT-1 distribution (McFadden, 1974) with zero mean, i.e., $F\left(\epsilon_{i k t}\right)=e^{-e^{-\epsilon_{i k t}-\gamma}}$ where $\gamma$ is Euler's constant, then Small and Rosen (1981) imply that the continuation payoff can be recursively written as follows:

$V_{t+1}(k)=\ln \left(\sum_{l \in D} e^{w_{l t+1}-c_{k l}+\beta V_{t+2}(l)}\right)$

\footnotetext{
6 The assumption that $c_{j k}$ is time-invariant is retained only to simplify the exposition of the theoretical model, but it is relaxed in the estimation.

7 This assumption, which has been introduced in influential dynamic discretechoice models (see, inter alia, Keane and Wolpin, 1997 and Lee, 2005) allows for providing a clearer analytical derivation of the dependence of current bilateral migration rates on the future attractiveness of alternative destinations; the inclusion of a stochastic aggregate component would complicate the model but would not alter the insights that can be derived from it.
} 
The probability that the individual $i$ will find it optimal to move from $j$ to $k$ at time $t$ is given by:

$p_{j k t}=\frac{e^{w_{k t}-c_{j k}+\beta V_{t+1}(k)}}{\sum_{l \in D} e^{w_{l t}-c_{j l}+\beta V_{t+1}(l)}}$

We let $P^{(t)}$ denote the $n \times n$ square matrix that describes the transition probabilities at time $t$ among the elements of the choice set $D$. Using Eq. (3) for period $t+1$, we can decompose the continuation payoff $V_{t+1}(k)$ in Eq. (2) into two components, as $V_{t+1}(k)=$ $w_{k t+1}+\Omega_{t+1}(k)$, where $w_{k t+1}$ represents the instantaneous payoff in $k$ at time $t+1$, and $\Omega_{t+1}(k) \equiv-\ln \left(p_{k k t+1}\right)>0$ is the value of the option of leaving location $k$ at time $t+1$ (Artuç et al., 2010). If we take the logarithm of the ratio of the probability of opting for country $k$ over the probability of staying in country $j$ in period $t$, with the normalization $c_{j j}=0, \forall j \in D$, then we get:

$\ln \left(\frac{p_{j k t}}{p_{j j t}}\right)=w_{k t}-w_{j t}-c_{j k}+\beta\left[V_{t+1}(k)-V_{t+1}(j)\right]$

The expression in Eq. (4) depends on: ( $i$ ) the difference between the deterministic component of utility at time $t$ in $k$ and in $j$ only, (ii) on the bilateral moving $\operatorname{cost} c_{j k}$, and on (iii) the difference in the discounted value of the continuation payoffs. The continuation payoffs depend on the future evolution of the attractiveness of all locations in the choice set, and on the whole matrix $C$. The dependence of the logarithm of the ratio of the two choice probabilities in Eq. (4) on the future attractiveness and accessibility of other locations in the choice set would disappear only if one of these two assumptions holds: ( $i$ ) individuals take myopic decisions, i.e., $\beta=0$, (ii) there are no migration costs, as this would imply that $V_{t+1}(k)=V_{t+1}(j)$, $\forall j, k \in D$. If one of these two (implausible) assumptions does not hold, then any estimation of the empirical counterpart of Eq. (4) that disregards the term $\beta\left[V_{t+1}(k)-V_{t+1}(j)\right]$ would be exposed to the threat to identification due to multilateral resistance to migration (Bertoli and Fernández-Huertas Moraga, 2013), as $\ln \left(p_{j k t} / p_{j j t}\right)$ also depends on the (future) attractiveness of alternative destinations.

We want to estimate the empirical counterpart of Eq. (4), with data on migration rates $y_{j k t}$ from multiple origins to a single destination (Germany, in our case) for $t=1, \ldots, T$. The inclusion of time dummies $\mathbf{d}_{t}$ allows us to control for the contemporary attractiveness $w_{k t}$ of the (single) destination country $k$ and for the continuation payoff $V_{t+1}(k)$, while the time-invariant component of bilateral migration cost $c_{j k}$ can be controlled through the inclusion of a vector of origin dummies $\mathbf{d}_{j} .{ }^{8}$ We assume that the instantaneous payoff $w_{j t}$ can be modeled as a linear function of a vector of time-varying origin-specific variables, i.e., $w_{j t}=\boldsymbol{\alpha}^{\prime} \mathbf{x}_{j t}{ }^{9}$ We will first estimate the following regression, which we will refer to as the FE (fixed effects) specification: ${ }^{10}$

$\ln \left(y_{j t}\right)=\boldsymbol{\alpha}^{\prime} \mathbf{x}_{\mathbf{j t}}+\boldsymbol{\phi}_{t}{ }^{\prime} \mathbf{d}_{\mathbf{t}}+\boldsymbol{\phi}_{j} \mathbf{d}_{\mathbf{j}}+\varepsilon_{j t}$

The error term in Eq. (5) is given by $\varepsilon_{j t}=-\beta V_{t+1}(j)+\eta_{j t}$; even if we assume that $\eta_{j t}$ is well-behaved and orthogonal to $\mathbf{x}_{j t}$, the estimates will be biased and inconsistent if we do not adequately control for $V_{t+1}(j)$. This threat to identification arises because the continuation payoff will be, in general, correlated with $\mathbf{x}_{j t}$, as $V_{t+1}(j)$

\footnotetext{
8 The estimation will also control for time-varying origin-specific components of migration costs.

9 The inclusion of origin dummies $\mathbf{d}_{j}$ also controls for the time-invariant component of the attractiveness of each origin country.

10 We omit the subscript $k$ from the bilateral migration rate from $j$ to $k$ as we have one single destination.
}

is a function both of $\mathbf{x}_{j s}$ and of $\mathbf{x}_{l s}$, for any $s \geq t+1$ and $l \neq j$, and the attractiveness of a destination is likely to evolve slowly over time. This represents a relevant threat to identification in our case, as we will be focusing on a set of European countries that also represented relevant destinations for other countries in the region and that experienced an economic crisis with relevant shared components between 2008 and 2014. In such a case, the direct effect of, say, a rise in the Italian unemployment on migration flows from Italy to Germany can be confounded by the simultaneous deterioration of labor market conditions in Spain and by the anticipation of hysteresis in unemployment (e.g., Galí, 2015), which might have redirected the flow of Italian migrants from Spain to Germany. Thus, the magnitude of the estimated effect for unemployment at origin would be upward biased, as predicted also by Bertoli and Fernández-Huertas Moraga (2013). More specifically, the presence of positive serial and cross-sectional correlation in the regressors entails that the biases arising from the estimation of the FE model are identical irrespective of whether the true underlying theoretical model is a static one with more general distributional assumptions as in Bertoli and Fernández-Huertas Moraga (2013), or a dynamic one with i.i.d. EVT-1 disturbances, as the one presented above, so that there is a fundamental observational equivalence between the two. ${ }^{11}$

As shown in the online Appendix A.1, this threat to identification can be dealt with by relying on the Common Correlated Effects estimator introduced by Pesaran (2006), ${ }^{12}$ through the estimation of the following regression:

$\ln \left(y_{j t}\right)=\boldsymbol{\alpha}^{\prime} \mathbf{x}_{\mathbf{j t}}+\boldsymbol{\phi}_{t}{ }^{\prime} \mathbf{d}_{\mathbf{t}}+\boldsymbol{\phi}_{j}{ }^{\prime} \mathbf{d}_{\mathbf{j}}+\boldsymbol{\lambda}_{j}{ }^{\prime} \tilde{\mathbf{z}}_{t}+\eta_{j t}$

where the vector of auxiliary regressors $\tilde{\mathbf{z}}_{t}$ is formed by the crosssectional averages of the dependent variable $\ln \left(y_{j t}\right)$ and of all the independent variables in the vector $\mathbf{x}_{j t}$. The estimation of Eq. (6), which we will term the CCE (common correlated effects) specification, delivers an unbiased estimate of $\alpha$ even in the presence of the confounding influence exerted by the future attractiveness of the various options in the choice set, while Eq. (5), the FE specification, does not. ${ }^{13}$

If, at time $t$, we have data about a vector of variables $\mathbf{q}_{j t}$ which is informative about the variations in the future attractiveness of the origin country $j$ for $s \geq t+1$ with respect to its current attractiveness, then we could augment either of the two Eqs. (5) or (6) with these variables. This can provide suggestive evidence about the extent to which current migration decisions respond to variations in the anticipations about the future attractiveness of the origin country. This approach entails a departure from the theoretical model, as we know that $V_{t+1}(j)$ depends on the future attractiveness of all locations rather than of $j$ alone.

\section{Data sources and descriptive statistics}

We describe here the variables, together with the various data sources they are drawn from, that we employ in our analysis of the determinants of the bilateral migration flows from all the countries in the EU to Germany.

\footnotetext{
11 We thank an anonymous referee for pointing out the existence of this observational equivalence.

12 See Eberhardt et al. (2013) for a non-technical introduction to the CCE estimator. 13 Notice that Eq. (6) represents a generalization of Eq. (5), as including time dummies $\mathbf{d}_{t}$ is equivalent to including the vector of auxiliary regressors $\tilde{\mathbf{z}}_{t}$ with a vector of coefficients that is invariant across origins; this entails that an F-test on the null hypothesis that $\lambda_{j}=\lambda, \forall j \in D$ can guide us with respect to the selection of our preferred specification.
} 


\subsection{Migration data}

The data on gross migration inflows are derived from a special data provision by the Federal Statistical Office (Statistisches Bundesamt, 2015), which has been collecting monthly data series on the arrivals of foreigners by country of origin, defined as the country of last residence before moving to Germany, since January 2006. ${ }^{14,15}$ We use data from January 2006 until September 2014, that is 105 monthly observations for each country of origin. These figures are based on the population registers that are kept at the municipal level. Registration is mandatory in Germany, as stated by the German registration law approved in March 2002 (Melderechtsrahmengesetz). The law does not subordinate the need to register to a minimum duration or to the scope of the stay, though there are exceptions for foreign citizens whose intended duration of stay in Germany is below two months, so that tourists do not have an obligation to register.

The inscription in the local population registry is a necessary precondition to obtain the income tax card that is required to sign any employment contract (including for seasonal work), to issue an invoice if self-employed and to rent a flat, as landlords usually require a proof that their would-be tenants have registered. Furthermore, the municipalities have an incentive to record new residents properly since their tax revenues depend on the number of registered inhabitants, so that fees are levied against the persons who do not comply with the mandatory registration. This ensures not only that immigrants register, but also that they do so shortly after their arrival, so that the figures from Statistisches Bundesamt (2015) give us an accurate representation of the timing of gross bilateral migration flows. ${ }^{16}$

Our main sample is thus composed by 27 origin countries, whose bilateral gross migration flows are observed over 105 months, i.e., $27 \times 105=2,835$ observations, with the total number of arrivals of foreigners that entered into Germany over the period standing at $4,391,282$. EU origins represent $63.5 \%$ of total gross inflows of migrants to Germany over our period of analysis. Fig. 1 plots the seasonally adjusted ${ }^{17}$ monthly gross migration flows from the countries in our sample to Germany over our period of analysis. Gross inflows fluctuated approximately between 25,000 and 30,000 per month until 2010, when the gross flows started to increase markedly, reaching by 2014 levels that were more than twice as large as they used to be over the 2006-2009 period. The main country of origin in absolute terms is represented by Poland (1,319,035 migrants over the period), followed by Romania $(740,675)$ and Bulgaria $(348,035)$. Some of the countries that have been more severely hit by the crisis also sent large numbers of migrants to Germany, with Italy being the fifth largest origin $(285,081$ migrants), Spain the sixth $(165,419)$ and Greece the seventh $(159,346)$.

The dependent variable in our econometric analysis is represented by the log of the bilateral migration rate from each origin country to Germany. We draw the information on the mid-year size of the population at origin, which is used for defining our

\footnotetext{
14 The inflows of the so-called ethnic Germans (Spätaussiedler) are not included, as they are reported together with the number of German returnees; all our results are robust to the inclusion of German returnees and ethnic Germans in the definition of the size of incoming bilateral migration flows.

15 As usual with migration data derived from population registers, the same individual can be counted more than once; with a minor abuse of terminology, we will be referring to the number of arrivals as the number of incoming migrants.

16 The limited incidence of informal employment in Germany suggests that the number of illegal migrants not covered by this administrative data source for the countries of origin is likely to be small, even at the time in which the mobility of labor from some countries was subject to legal restrictions, as discussed in Section 3.3 below; no European country is among the top ten of the largest irregular communities according to the estimates provided by Schneider (2012) and Vogel and Assner (2011).

17 See the description of how we seasonally adjust variables below.
}

dependent variable and to weigh the observations in our sample, ${ }^{18}$ from Eurostat (2015c).

\subsection{Current economic conditions}

We rely on seasonally adjusted data on unemployment rates, measured at a monthly frequency, as a measure of the current economic conditions for each country in our sample. The data come from Eurostat (2015b). Real GDP figures are available only at a lower, i.e., quarterly, frequency, and this motivates our choice of the unemployment rate as a measure of current economic conditions. ${ }^{19}$

\subsection{Migration policies}

The sample of origin countries included in our empirical analysis is composed by the 27 countries that, together with Germany, were members of the European Union by 2014. Bulgaria and Romania joined the EU in January 2007, while the accession of Croatia dates to January 2014. The citizens of eight of the countries that joined the EU in May 2004 (namely Czech Republic, Estonia, Hungary, Latvia, Lithuania, Poland, Slovak Republic and Slovenia) were subject to a transitional period that imposed restrictions on the free movement of labor to Germany that came to an end in May 2011, ${ }^{20}$ and a similar seven-year transitional period for Bulgaria and Romania ended in January 2014. We build dummies to keep track of these institutional and policy changes, which are also reported in Fig. 1, that can influence the time profile of gross migration inflows from some of the origin countries in our sample to Germany.

\subsection{Expectations}

We introduce two main proxies for the anticipations about the future attractiveness of the origin countries in our sample. First, we rely on monthly data from Consumer Surveys by the European Commission to have information on the anticipations about the evolution of various dimensions of the economic situation over the next 12 months for each country (European Commission, 2015). Specifically, we employ the synthetic measure of expectations that aggregates anticipations about ( $i$ ) the household financial position, (ii) general economic situation of the country, (iii) the number of unemployed people, and (iv) the likelihood of saving money. ${ }^{21}$ This variable, which is described in detail in Appendix A.2, is given by the arithmetic average of the indicator concerning each of these four aspects, which ranges between -100 , when all respondents anticipate a very negative evolution, and 100 , which correspond to very favorable anticipations reported by all respondents.

The second proxy for expectations that is used in our analysis is represented by the yields on the secondary market of government bonds with a residual maturity of 10 years, which are drawn from the European Central Bank (2015). ${ }^{22}$ Theevolution of sovereign bond yields reflects the evolution of three main factors: the real

\footnotetext{
18 As it is common in the literature, this the logarithm of the ratio between the gross flow of migrants from $j$ to $k$ at time $t$ over the size of the total population at origin at time $t$; this definition drives a wedge with the theoretical model, as the denominator of the ratio should actually be represented by the portion of the population that chose to stay at origin at time $t$, while the total population also includes immigrants and returnees. We provide evidence below that this proxy of the theoretically relevant concept does not influence our estimates.

19 All our results are robust to the inclusion of real GDP among the regressors.

20 Cyprus and Malta also joined the EU in 2004 but the right to the free movement of labor was immediately granted to their citizens.

21 All our results are robust to the use of the monthly data on the Economic Sentiment Indicator by the European Commission, which is built combining expectations on the evolution of business conditions in four distinct sectors (industry, services, construction, and retail trade) with the measure of consumers' confidence that we use in the analysis; results are available from the authors upon request.

22 See Appendix A.3 for further details on this variable.
} 




Source: Authors' elaboration on Statistisches Bundesamt (2015).

Fig. 1. Seasonally-adjusted monthly gross migration flows to Germany from EU countries.

interest rate, the expected inflation rate, and the risk premium. The relationship between a variation in the sovereign bond yields and the expectations about future economic conditions is, in general, ambiguous, as an increase in the real interest rate due to sustained economic growth or an increase in the risk premium demanded by investors convey opposite signals. Nevertheless, such an ambiguity did not apply to European countries over our period of analysis, as the economic crisis in Europe was characterized by important fluctuations in the interest rate on government bonds mostly due to variations in the risk premium, with increases being associated with the expectation of a fiscal consolidation, which induced a deterioration of macroeconomic conditions (Blanchard and Leigh, 2013). To strengthen this argument, Fig. 2 plots the evolution of the synthetic measure of consumers' confidence and the 10-year bond yields between January 2006 and September 2014 for Greece, one of the countries that was most severely hit by the crisis. The similarity in the time profile of the two series is remarkable, as the surge in the interest rate recorded after January 2010 is associated with a marked deterioration in the expectations about future economic conditions in Greece, while the famous speech by Mario Draghi, on July $26,2012,{ }^{23}$ is followed by a decline in interest rates and an improvement in expectations. The association between these two proxies for expectations is not limited to the Greek case, as a multivariate analysis with origin and month fixed effects reveals that a $1 \%$ increase in bond yields is associated with a $-0.39 \%$ (s.e. 0.01 ) reduction in the synthetic measure of consumer confidence. This, in turn, justifies our hypothesis that a rise in the yields of sovereign bonds is associated with the expectation of deteriorating economic conditions.

\footnotetext{
23 "Within our mandate, the ECB is ready to do whatever it takes to preserve the euro. And believe me, it will be enough." (source: https://www.ecb.europa.eu/press key/date/2012/html/sp120726.en.html, accessed on June 2, 2015).
}

\subsection{Descriptive statistics}

Table 1 presents the descriptive statistics for bilateral migration rates, unemployment rates, consumer confidence and the 10 -year bond yields, separately for each of the origin countries in our sample and as a population-weighted average over the entire sample. Table 1 reveals that some Eastern European countries (namely Bulgaria, Romania, Hungary and Poland) recorded the highest average monthly migration rates to Germany over our period of analysis. If we consider the yearly migration, this stood on average at $0.10 \times$ $12=1.2$ per thousand over our sample of origin countries according to Table 1.

We also see how the various origin countries in our sample experienced major differences both in the level and in the variability (as reflected by the difference between the highest and the lowest value) with respect to the other variables included in the analysis: the unemployment rate reached 26.3 and $28.0 \%$ respectively for Spain and Greece, while all countries in the sample except Denmark, Finland and Sweden had, on average, negative expectations on the evolution of their economic situation. The yields on 10-year government bonds also greatly differed across countries, with peaks that exceeded (at times greatly so) 10\% for seven out of 27 origin countries.

\section{Estimates}

We describe in detail the exact specifications that we will be taking to the data before proceeding with the results, and we discuss the expected direction of the bias in the estimation of the various coefficients that is due to the threats to identification to which Eq. (5) is exposed.

First, the vector $\mathbf{x}_{j t}$ includes: $(i)$ the logarithm of the unemployment rate at origin, (ii) a dummy that identifies whether the origin $j$ was a EU member at time $t$ (EU accession variable), (iii) a 


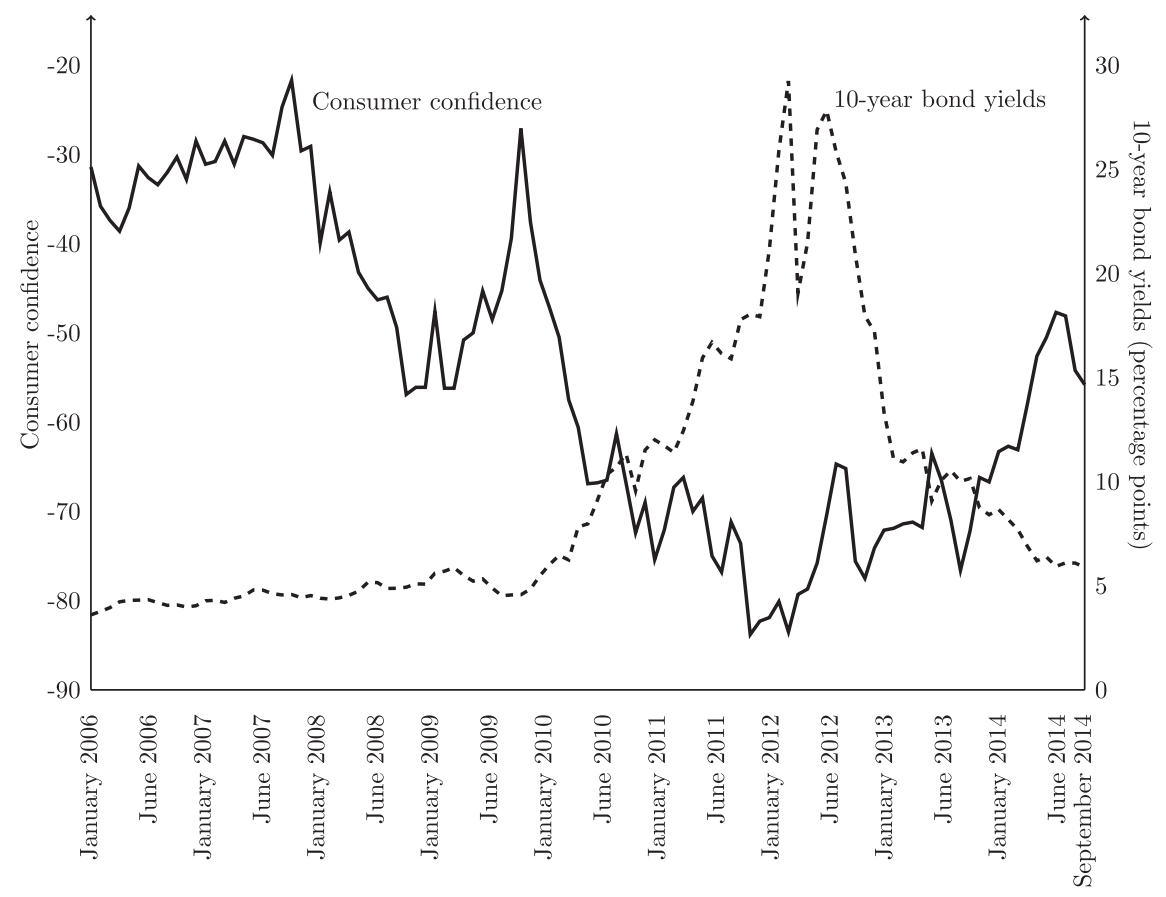

Source: Authors' elaboration on European Commission (2015) and European Central Bank (2015).

Fig. 2. Consumer confidence and 10-year bond yields for Greece.

dummy that identifies whether the citizens of the origin $j$ benefited from no restrictions on their movement to Germany at time $t$ (free mobility variable). In some specification we also include (iv) the logarithm of either of our two proxies for expectations, namely consumer confidence or the 10-year bond yields. Changes in current economic conditions or in expectations about their future evolution need not produce an instantaneous effect on bilateral migration flows to Germany, so that the vector $\mathbf{x}_{j t}$ in Eqs. (5) and (6) should

Table 1

Descriptive statistics.

\begin{tabular}{|c|c|c|c|c|c|c|c|c|c|c|c|c|}
\hline \multirow[b]{2}{*}{ Country } & \multicolumn{3}{|c|}{ Migration rate } & \multicolumn{3}{|c|}{ Unemployment rate } & \multicolumn{3}{|c|}{ Consumer confidence } & \multicolumn{3}{|c|}{ Bond yields } \\
\hline & Mean & Min. & Max. & Mean & Min. & Max. & Mean & Min. & Max. & Mean & Min. & Max. \\
\hline All origins & 0.10 & 0.00 & 1.14 & 9.58 & 3.1 & 28.0 & -19.23 & -83.8 & 28.0 & 4.42 & 0.96 & 29.24 \\
\hline Austria & 0.11 & 0.06 & 0.18 & 4.50 & 3.5 & 5.3 & -1.39 & -23.0 & 16.3 & 3.26 & 1.22 & 4.80 \\
\hline Belgium & 0.02 & 0.01 & 0.05 & 7.84 & 6.8 & 8.8 & -9.09 & -26.5 & 2.9 & 3.54 & 1.30 & 4.85 \\
\hline Bulgaria & 0.45 & 0.05 & 1.14 & 9.60 & 5.1 & 13.2 & -36.87 & -50.1 & -20.8 & 4.94 & 3.11 & 7.77 \\
\hline Croatia & 0.28 & 0.09 & 1.10 & 12.69 & 7.6 & 18.2 & -33.81 & -51.5 & -14.0 & 5.72 & 3.57 & 8.64 \\
\hline Cyprus & 0.04 & 0.00 & 0.21 & 8.17 & 3.2 & 16.8 & -38.48 & -64.4 & -25.2 & 5.28 & 3.96 & 7.00 \\
\hline Czech Republic & 0.07 & 0.02 & 0.15 & 6.41 & 4.2 & 7.8 & -12.09 & -31.2 & 3.9 & 3.59 & 1.21 & 5.45 \\
\hline Denmark & 0.04 & 0.01 & 0.07 & 5.90 & 3.1 & 7.9 & 10.13 & -7.4 & 20.4 & 2.95 & 0.96 & 4.82 \\
\hline Estonia & 0.06 & 0.02 & 0.16 & 9.49 & 4.0 & 19.0 & -7.48 & -38.0 & 12.8 & 5.38 & 4.97 & 6.24 \\
\hline Finland & 0.03 & 0.01 & 0.10 & 7.72 & 6.2 & 8.8 & 11.15 & -6.4 & 23.8 & 3.09 & 1.13 & 4.78 \\
\hline France & 0.02 & 0.01 & 0.04 & 9.10 & 7.2 & 10.3 & -20.16 & -37.0 & 1.8 & 3.26 & 1.35 & 4.73 \\
\hline Greece & 0.14 & 0.04 & 0.35 & 15.73 & 7.3 & 28.0 & -54.41 & -83.8 & -21.7 & 9.24 & 3.60 & 29.24 \\
\hline Hungary & 0.30 & 0.09 & 0.64 & 9.36 & 7.1 & 11.4 & -40.18 & -68.8 & -10.4 & 7.29 & 4.33 & 11.65 \\
\hline Ireland & 0.03 & 0.01 & 0.08 & 10.61 & 4.3 & 15.1 & -13.31 & -32.1 & 13.9 & 5.16 & 1.65 & 11.70 \\
\hline Italy & 0.05 & 0.02 & 0.13 & 8.73 & 5.8 & 12.9 & -22.99 & -41.5 & -8.7 & 4.47 & 2.40 & 7.06 \\
\hline Latvia & 0.24 & 0.04 & 0.53 & 12.47 & 5.5 & 20.6 & -20.00 & -54.9 & 1.0 & 6.22 & 2.28 & 13.76 \\
\hline Lithuania & 0.18 & 0.06 & 0.36 & 11.02 & 4.0 & 18.3 & -18.01 & -56.1 & 9.2 & 5.70 & 2.42 & 14.50 \\
\hline Luxembourg & 0.41 & 0.19 & 1.00 & 4.98 & 4.0 & 6.0 & -2.79 & -20.7 & 11.0 & 3.14 & 0.98 & 5.01 \\
\hline Netherlands & 0.05 & 0.03 & 0.08 & 5.25 & 3.6 & 7.9 & -3.82 & -30.2 & 20.3 & 3.09 & 1.15 & 4.73 \\
\hline Poland & 0.33 & 0.11 & 0.59 & 9.77 & 6.8 & 16.1 & -18.56 & -35.9 & -0.5 & 5.32 & 3.10 & 6.45 \\
\hline Portugal & 0.06 & 0.02 & 0.13 & 12.03 & 8.5 & 17.5 & -40.15 & -60.1 & -23.3 & 6.00 & 3.18 & 13.85 \\
\hline Romania & 0.35 & 0.05 & 1.05 & 6.70 & 5.5 & 7.2 & -33.38 & -63.3 & -10.6 & 7.09 & 4.09 & 11.46 \\
\hline Slovak Republic & 0.17 & 0.06 & 0.33 & 12.90 & 8.7 & 15.0 & -19.74 & -45.4 & 6.6 & 4.13 & 1.57 & 5.42 \\
\hline Slovenia & 0.12 & 0.03 & 0.37 & 7.20 & 4.2 & 10.7 & -23.78 & -46.1 & -4.1 & 4.62 & 2.66 & 6.90 \\
\hline Spain & 0.03 & 0.01 & 0.12 & 17.89 & 7.9 & 26.3 & -21.57 & -47.6 & -3.9 & 4.43 & 2.16 & 6.80 \\
\hline Sweden & 0.02 & 0.01 & 0.05 & 7.54 & 5.6 & 9.3 & 12.84 & -10.0 & 28.0 & 2.93 & 1.33 & 4.45 \\
\hline United Kingdom & 0.01 & 0.01 & 0.03 & 6.84 & 5.0 & 8.4 & -12.15 & -35.2 & 7.6 & 3.53 & 1.65 & 5.43 \\
\hline Malta & 0.03 & 0.00 & 0.20 & 6.47 & 5.9 & 7.3 & -24.44 & -41.3 & 1.4 & 4.19 & 2.32 & 5.28 \\
\hline
\end{tabular}

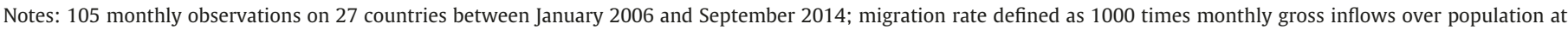
origin; consumer confidence varies between -100 and 100; bond yields in percentage points; the means for all origins are population-weighted.

Source: Authors' elaboration on Statistisches Bundesamt (2015), Eurostat (2015a,b,c), European Commission (2015) and European Central Bank (2015). 
Table 2

Determinants of bilateral migration to Germany (2006-2014).

\begin{tabular}{|c|c|c|c|c|c|c|}
\hline \multirow{3}{*}{$\begin{array}{l}\text { Dependent variable } \\
\text { Expectations variable } \\
\text { Model }\end{array}$} & \multicolumn{6}{|c|}{ Log of the bilateral migration rate to Germany } \\
\hline & \multirow[b]{2}{*}{ FE } & \multirow[b]{2}{*}{ CCE } & \multicolumn{2}{|c|}{ Consumer confidence } & \multicolumn{2}{|c|}{ Bond yields } \\
\hline & & & $\mathrm{FE}$ & CCE & FE & CCE \\
\hline Variables & (1) & $(2)$ & (3) & $(4)$ & (5) & (6) \\
\hline Log unemployment rate & 0.871 & 0.538 & 0.847 & 0.475 & 0.628 & 0.394 \\
\hline (four lags) & {$[0.021]$} & {$[0.027]$} & {$[0.022]$} & [0.029] & {$[0.020]$} & [0.033] \\
\hline Log expectations & & & -0.110 & -0.137 & 0.460 & 0.121 \\
\hline (four lags) & & & {$[0.024]$} & {$[0.020]$} & {$[0.015]$} & [0.016] \\
\hline \multirow[t]{2}{*}{ EU accession } & 1.207 & 1.042 & 1.195 & 0.907 & 1.136 & 1.039 \\
\hline & {$[0.041]$} & {$[0.065]$} & {$[0.041]$} & {$[0.082]$} & {$[0.035]$} & {$[0.073]$} \\
\hline \multirow{2}{*}{ Free mobility } & 0.239 & 0.304 & 0.236 & 0.384 & 0.205 & 0.340 \\
\hline & {$[0.019]$} & {$[0.026]$} & {$[0.019]$} & {$[0.033]$} & {$[0.016]$} & {$[0.029]$} \\
\hline CCE test ( $p$-value) & \multicolumn{2}{|c|}{$47.18(0.00)$} & \multicolumn{2}{|c|}{$34.27(0.00)$} & \multicolumn{2}{|c|}{$24.57(0.00)$} \\
\hline Time dummies & Yes & Yes & Yes & Yes & Yes & Yes \\
\hline Origin seasonal dummies & Yes & Yes & Yes & Yes & Yes & Yes \\
\hline Auxiliary regressors & No & Yes & No & Yes & No & Yes \\
\hline Adjusted $R^{2}$ & 0.975 & 0.994 & 0.975 & 0.995 & 0.982 & 0.995 \\
\hline Countries & 27 & 27 & 27 & 27 & 27 & 27 \\
\hline Observations & 2835 & 2835 & 2835 & 2835 & 2835 & 2835 \\
\hline
\end{tabular}

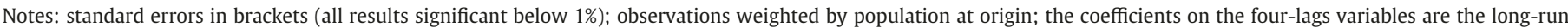

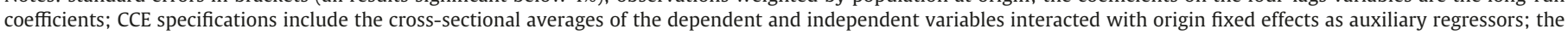
null of the CCE test (F-test) is that the coefficients of the cross-sectional averages included as auxiliary regressors do not vary across origins.

Source: Authors' elaboration on the data presented in Section 3.

also include some lagged terms. We follow Canova (2007), selecting the optimal number of lags by running successive LR tests on dropping higher order lags. ${ }^{24}$ The result is that we include four lags of the three variables, i.e., the unemployment rate and the two proxies for expectations, in our monthly data regressions. What we report below is the long-run coefficient associated to each specification, that is, the sum of the lags for each of the variables. ${ }^{25}$ We also rely on lower frequency, i.e., quarterly and yearly, data to estimate our model, in order to address the concern that our estimated elasticities with monthly data do not capture the full response of international migration flows to variations in their underlying determinants. The elasticities estimated with quarterly and yearly data are in line with, and not statistically different from, those obtained with monthly data, and this is reassuring with respect to our choice to rely on highfrequency data for the estimation, which allows us to better capture sharp variations in the attractiveness or accessibility of the various locations in the choice set. ${ }^{26}$

Second, we include a rich variety of fixed effects when estimating Eqs. (5) and (6), which allows us to control for many unobserved determinants of bilateral migration flows. In particular, we include time dummies $\left(\mathbf{d}_{t}\right)$. These dummies absorb any German-specific variation in the data, as well as common elements across countries of origin over time. For instance, the effect of current German economic conditions or German general migration policies is absorbed by our time fixed effects. Importantly, the time dummies $\mathbf{d}_{t}$ also absorb the influence of the continuation payoff $V_{t+1}(k)$ on $\ln \left(y_{j t}\right)$. We also include origin-specific fixed effects $\left(\mathbf{d}_{j}\right)$, which control for timeinvariant bilateral determinants of migration flows to Germany, such as cultural, linguistic and geographical distance. The origin dummies $\mathbf{d}_{j}$ also absorb the effect of any bilateral policy or institutional

\footnotetext{
$\overline{24}$ The highest number of lags that we included was four, as Canova (2007) suggests to include a number of lags that does not exceed $T^{1 / 3}$, with this limit being 4.7 in our dataset with $T=105$ observations for each country; both the Akaike and Bayesian Information Criteria select the same number of lags.

25 All of our results hold if we also add lags of the dependent variable; the results are available from the authors upon request.

26 Yearly data allow us to estimate only FE specifications, while quarterly data have a longitudinal dimension that allow us to run also CCE specifications; results are available from the authors upon request.
}

variable that does not vary over our period of analysis. ${ }^{27}$ Our originspecific fixed effects also partly control for slowly moving bilateral or origin-specific variables, such as the demographic composition of the population at origin, that barely changed between 2006 and 2014. The origin dummies $\mathbf{d}_{j}$ might be only partly controlling for the influence on migration flows exerted by migration networks, as the size of some communities of European migrants in Germany substantially increased over our period of analysis. We control for this confounding effect through the inclusion of interactions between the origin fixed effects $\mathbf{d}_{j}$ and dummies for sub-periods of our dataset in some of our specifications. ${ }^{28}$

Finally, we also control for country-specific seasonal patterns in the data (also included in $\mathbf{x}_{j t}$ ). While the inclusion of these controls does not affect our results, they improve the fit of the models that we present. Thus, we add origin-country times month-of-the-year fixed effects to absorb these origin-specific seasonal patterns. ${ }^{29}$ The rich structure of fixed effects that we rely upon for the estimation of both Eqs. (5) and (6) implies that the identifying variation comes from the correlation between the origin-specific evolution of the seasonally adjusted dependent variable and of the seasonally adjusted regressors, net of common time effects. ${ }^{30}$ In our preferred specifications, we weight observations by the population of the origin country, ${ }^{31}$

\footnotetext{
27 As the citizens of all countries in our sample benefited from a visa waiver for non-immigrant admission to Germany throughout our period of analysis, then origin dummies also absorb in this case the effect produced by bilateral visa policies on bilateral migration flows (Bertoli and Fernández-Huertas Moraga, 2015).

28 Specifically, we will introduce interactions between $\mathbf{d}_{j}$ and dummies for four subperiods of roughly equal length ( 26 months for the first three sub-periods and 27 months for the last one) of our sample.

29 This is equivalent to first regressing separately the dependent and each of the independent variables (including the auxiliary regressors for the CCE estimation) on the interaction between origin dummies and month-of-the-year dummies, and then estimating the model on the residuals generated by these regressions; this is what we mean when we refer to seasonally adjusted data.

30 The inclusion of interactions between origin dummies and dummies for time subperiods in some specifications further reduces the identifying variation, removing the variability across sub-periods for each origin.

31 This is the theoretically relevant specification since it ensures that the location decision of each individual is weighted in the same way, independently of her country of origin; Bertoli and Fernández-Huertas Moraga (2013) or Hanson and McIntosh (2012), among others, follow this approach.
} 
Table 3

Determinants of bilateral migration to Germany (2006-2014), controlling for origin-specific time-varying unobservables.

\begin{tabular}{|c|c|c|c|c|c|c|}
\hline \multirow{3}{*}{$\begin{array}{l}\text { Dependent variable } \\
\text { Expectations variable } \\
\text { Model }\end{array}$} & \multicolumn{6}{|c|}{ Log of the bilateral migration rate to Germany } \\
\hline & \multirow[b]{2}{*}{$\mathrm{FE}$} & \multirow[b]{2}{*}{ CCE } & \multicolumn{2}{|c|}{ Consumer confidence } & \multicolumn{2}{|c|}{ Bond yields } \\
\hline & & & FE & CCE & FE & CCE \\
\hline Variables & (1) & (2) & (3) & (4) & (5) & (6) \\
\hline Log unemployment rate & 0.529 & 0.502 & 0.504 & 0.422 & 0.501 & 0.396 \\
\hline (four lags) & [0.028] & {$[0.040]$} & {$[0.028]$} & {$[0.045]$} & {$[0.028]$} & [0.047] \\
\hline Log expectations & & & -0.098 & -0.079 & 0.166 & 0.087 \\
\hline (four lags) & & & [0.019] & {$[0.028]$} & {$[0.016]$} & [0.019] \\
\hline \multirow[t]{2}{*}{ EU accession } & 0.789 & 0.999 & 0.794 & 0.919 & 0.798 & 1.004 \\
\hline & [0.027] & {$[0.068]$} & {$[0.027]$} & {$[0.086]$} & {$[0.027]$} & {$[0.078]$} \\
\hline \multirow{2}{*}{ Free mobility } & 0.241 & 0.305 & 0.233 & 0.325 & 0.253 & 0.310 \\
\hline & [0.017] & {$[0.026]$} & {$[0.017]$} & {$[0.034]$} & {$[0.016]$} & {$[0.030]$} \\
\hline CCE test ( $p$-value) & \multicolumn{2}{|c|}{$6.52(0.00)$} & \multicolumn{2}{|c|}{$4.88(0.00)$} & \multicolumn{2}{|c|}{$4.56(0.00)$} \\
\hline Time dummies & Yes & Yes & Yes & Yes & Yes & Yes \\
\hline Origin seasonal dummies & Yes & Yes & Yes & Yes & Yes & Yes \\
\hline Origin-period dummies & Yes & Yes & Yes & Yes & Yes & Yes \\
\hline Auxiliary regressors & No & Yes & No & Yes & No & Yes \\
\hline Adjusted $R^{2}$ & 0.993 & 0.995 & 0.993 & 0.995 & 0.994 & 0.996 \\
\hline Countries & 27 & 27 & 27 & 27 & 27 & 27 \\
\hline Observations & 2835 & 2835 & 2835 & 2835 & 2835 & 2835 \\
\hline
\end{tabular}


and July 2012 to September 2014; see also the notes to Table 2.

Source: Authors' elaboration on the data presented in Section 3.

although this choice does not influence the results that we obtained, as shown below in Section 4.2.

The two gravity equations deliver consistent estimates under different assumptions of the dynamic discrete choice model that describes the location-decision problem that potential migrants face; specifically, the derivation of Eq. (5) rests on the assumption that either migrants are myopic, as they disregard the future implications of their current location choices, or that there are no migration costs. If neither of these two implausible assumptions hold, then we can obtain consistent estimates through the estimation of Eq. (6), where we control for the threat to identification posed by the dependence of the current bilateral migration rate on the future attractiveness of all potential destination countries. This threat might be particularly relevant in this context, as several major migrant-recipient countries were severely affected by the economic crisis.

\subsection{Main specifications}

Column (1) of Table 2 reports the results obtained from the estimation of Eq. (5). The interpretation of the long-run coefficient is straightforward: a $1 \%$ increase in the unemployment rate at origin is associated with a $0.87 \%$ increase in the emigration rate to Germany. The policy variables are also remarkable. Granting free mobility at the end of the transitional period was associated with an increase in the migration rate to Germany equal to $e^{0.239}-1 \approx 27 \%$, whereas the migration rate from Romania, Bulgaria and Croatia more than tripled ( $e^{1.207}-1 \approx 234 \%$ increase) after these countries became EU members.

The identification of these estimates is threatened by the fact that we are not controlling for the possible dependence of the current bilateral migration rates on the future attractiveness of alternative destinations, which represents a specific cause of multilateral resistance to migration. We tackle this threat to identification by adding the vector of auxiliary regressors $\tilde{\mathbf{z}}_{t}$ interacted with origin dummies $\mathbf{d}_{j}$ in the specification presented in Column (2) of Table $2 .{ }^{32}$ The value of the F-test on the assumption that the inclusion of these auxiliary regressors is actually unnecessary is 47.18 , thus strongly

32 For this specification, this requires to estimate 189 additional coefficients, corresponding to 27 origin-specific coefficients for each of the seven auxiliary regressors. rejecting the null that reflects the hypothesis that the origin-specific coefficients of the cross-sectional averages do not vary across origins. The rejection of the null suggests that the estimated elasticity for the unemployment rate in Column (1) may be biased. This is what the comparison of the estimates in Columns (1) and (2) actually reveals: the long-run elasticities of migration rates to Germany with respect to origin-country unemployment rates go down from 0.87 to 0.54 , a $38 \%$ reduction that signals that the previous estimate was, as expected, upward biased. Column (2) in Table 2 provides a consistent estimate of the effects of unemployment rates at origin on migration rates to Germany, ${ }^{33}$ even if we have omitted relevant observable or unobservable determinants of migration flows to Germany, and it thus represents our preferred specification.

Regarding our policy variables, we know that migration policies are generally coordinated at the European level. For example, the lifting of free mobility restrictions on workers for the citizens of the 2004 Enlargement countries (Czech Republic, Estonia, Hungary, Latvia, Lithuania, Poland, Slovakia and Slovenia) in May 2011 took place at the same time in Germany and in most of the other original EU member states. ${ }^{34}$ This suggests that the estimated effect for this variable from Column (1) in Table 2 might be downward biased, since the coefficient would simultaneously pick up both the positive direct effect on migration to Germany coming from lifting these restrictions and the negative indirect effect on migration to Germany coming from the simultaneous lifting of restrictions on alternative destinations, such as France. This is indeed the direction of the bias that we uncover for the free mobility dummy. The effect of this variable increases from $27 \%$ to $e^{0.304}-1 \approx 36 \%$ in Column (2). For the same reason, we would have expected the estimate on the EU accession dummy to be larger in Column (2) than in Column (1), while this is not actually the case, although the difference is not significant at conventional confidence levels. We will come back to this issue

\footnotetext{
33 While we cannot purely establish causality, the endogeneity generated by reverse causality between changes in migration rates at the monthly level and changes in unemployment is likely to be irrelevant for most countries in the sample, given that migration rates to Germany do not generally affect great shares of the origin population.

34 Ireland, the United Kingdom and Sweden had not introduced temporary restrictions on the free mobility of the citizens of the countries that joined the EU in May 2004
} 
Table 4

Determinants of bilateral migration to Germany (2006-2014), no weights.

\begin{tabular}{|c|c|c|c|c|c|c|}
\hline \multirow{3}{*}{$\begin{array}{l}\text { Dependent variable } \\
\text { Expectations variable } \\
\text { Model }\end{array}$} & \multicolumn{6}{|c|}{ Log of the bilateral migration rate to Germany } \\
\hline & \multirow[b]{2}{*}{$\mathrm{FE}$} & \multirow[b]{2}{*}{ CCE } & \multicolumn{2}{|c|}{ Consumer confidence } & \multicolumn{2}{|c|}{ Bond yields } \\
\hline & & & $\mathrm{FE}$ & CCE & $\mathrm{FE}$ & CCE \\
\hline Variables & (1) & (2) & (3) & (4) & (5) & (6) \\
\hline Log unemployment rate & 0.726 & 0.557 & 0.673 & 0.506 & 0.483 & 0.389 \\
\hline (four lags) & {$[0.024]$} & {$[0.041]$} & {$[0.025]$} & {$[0.048]$} & {$[0.025]$} & {$[0.061]$} \\
\hline Log expectations & & & -0.181 & -0.162 & 0.416 & 0.131 \\
\hline (four lags) & & & {$[0.028]$} & {$[0.036]$} & {$[0.021]$} & [0.034] \\
\hline \multirow[t]{2}{*}{ EU accession } & 1.150 & 1.043 & 1.141 & 0.945 & 1.104 & 1.025 \\
\hline & {$[0.047]$} & {$[0.060]$} & {$[0.046]$} & {$[0.076]$} & {$[0.043]$} & [0.081] \\
\hline \multirow[t]{2}{*}{ Free mobility } & 0.354 & 0.332 & 0.366 & 0.450 & 0.339 & 0.338 \\
\hline & {$[0.022]$} & {$[0.051]$} & {$[0.022]$} & [0.065] & {$[0.020]$} & [0.062] \\
\hline CCE test ( $p$-value) & \multicolumn{2}{|c|}{$17.85(0.00)$} & \multicolumn{2}{|c|}{$11.76(0.00)$} & \multicolumn{2}{|c|}{$9.96(0.00)$} \\
\hline Time dummies & Yes & Yes & Yes & Yes & Yes & Yes \\
\hline Origin seasonal dummies & Yes & Yes & Yes & Yes & Yes & Yes \\
\hline Auxiliary regressors & No & Yes & Yo & Yes & Yo & Yes \\
\hline Adjusted $R^{2}$ & 0.950 & 0.978 & 0.951 & 0.978 & 0.957 & 0.979 \\
\hline Countries & 27 & 27 & 27 & 27 & 27 & 27 \\
\hline Observations & 2835 & 2835 & 2835 & 2835 & 2835 & 2835 \\
\hline
\end{tabular}

Notes: see Table 2 .

Source: Authors' elaboration on the data presented in Section 3.

when discussing Table 3. Still, the effect of the EU accession dummy is remarkably large in the CCE specification: $e^{1.042}-1 \approx 183 \%$ increase in migration to Germany from Bulgaria, Romania and Croatia after entering the EU.

The estimates in Column (2) are already free from the threat to identification posed by the explicit consideration of expectations, but it is also interesting per se to gain an understanding of the role played by expectations in the decision to migrate to Germany, rather than just treating them as a nuisance. Thus, in Columns (3) to (6) in Table 2, we add (four lags of) our two measures of expectations: first the log of the general consumer confidence index in each our our origin countries in Columns (3) and (4), and second the log of the yields on sovereign bonds with a residual maturity of 10 years for each of our origin countries in Columns (5) and (6).

The estimates in the third data column reveal that a $10 \%$ increase in consumer confidence at origin is associated with a $1.1 \%$ decrease in the bilateral migration rate to Germany. Interestingly, the inclusion of our proxy for expectations barely affects the rest of estimated coefficients in Column (1). This suggests, as our theory predicts, that the inclusion of a direct estimate for expectations at origin is not enough to remove the bias due to the omission of proper controls for the value of the continuation payoff $V_{t+1}(j)$ from staying at origin. The reason is twofold: first, $V_{t+1}(j)$ depends in a highly non-linear way of the expectations at origin; second, the continuation payoff at origin also depends on expectations about the evolution of the attractiveness of all alternative destinations for potential migrants.

Given these considerations, we turn to Column (4), where we apply the CCE estimator to the augmented model, including both the lags of the consumer confidence variable and their cross-sectional averages interacted with origin fixed effects. The coefficient on the consumer confidence variable remains statistically at the same level as the one in Column (3): -0.14 versus -0.11 . For the other variables, the estimates in Column (3) reveal substantial biases, which we abstain from commenting since they are identical to the difference between the simpler models in Columns (1) and (2). The need for the CCE estimator is confirmed by the F-test, which stands at 34.27 , thus clearly rejecting the null.

When comparing Columns (2) and (4) in Table 2, which have both been estimated with the CCE methodology, we observe that the estimate on the unemployment rate goes down from 0.54 to 0.48 once we introduce our first proxy for expectations. The reason is that our proxy for expectations is correlated with the unemployment rate
( -0.40 in raw terms and -0.19 net of fixed effects) so that when the unemployment rate is considered in isolation, it picks up the effect both of current economic conditions and of current conditions correlated with future expectations. In Column (4), part of this second effect is absorbed by our proxy for expectations. ${ }^{35}$

Columns (5) and (6) repeat the exercise from Columns (3) and (4) by adding a different measure of expectations: the 10-year bond yields. The estimate from Column (5) reveal that a $10 \%$ rise in the 10 year bond yields was associated in this period with a $4.6 \%$ increase in the emigration rate of that country to Germany. In this case, the coefficient on the effect of the unemployment rate goes notably down with respect to Column (1): from 0.87 to 0.63 . This is not enough to absorb all the bias with respect to our preferred specification in Column (2) but the change goes in the expected direction, suggesting that the type of expectations associated with the evolution of the bond yields over the period could be more correlated with the continuation payoff in the origin country than the consumer confidence variable. In the case of the CCE specification, this time we see that the FE estimates were biased both for the unemployment rate, which goes from 0.63 to 0.39 , and for our proxy for expectations, the bond yields, from 0.46 to 0.12 . Again, the joint effect of the unemployment and bond yields variable in this specification is comparable to the isolated effect of the unemployment variable in Column (2).

\subsection{Robustness checks}

We present some relevant robustness checks on our results, where $(i)$ we more fully control for additional omitted unobservable variables through a richer structure of fixed effects, (ii) we do not weight observations, and (iii) we rely on alternative measures of population at origin. For all points we report the FE and the CCE estimates including the rate of unemployment at origin, our two expectations variables and immigration policy variables.

First, we include the interaction between the origin dummies $\mathbf{d}_{j}$ and dummies for four sub-periods of our sample: three sub-periods of 26 months (January 2006 to February 2008, March 2008 to April

\footnotetext{
35 The same thing happens when we add other variables proxying for current economic conditions; for example, if we add the GDP per capita as an explanatory variable, its correlation with the unemployment rate makes it pick up part of the effect of current economic conditions. Results available from the authors upon request.
} 
Table 5

Determinants of bilateral migration to Germany (2006-2014), alternative population.

\begin{tabular}{|c|c|c|c|c|c|c|}
\hline \multirow{3}{*}{$\begin{array}{l}\text { Dependent variable } \\
\text { Expectations variable } \\
\text { Model }\end{array}$} & \multicolumn{6}{|c|}{ Log of the bilateral migration rate to Germany } \\
\hline & \multirow[b]{2}{*}{$\mathrm{FE}$} & \multirow[b]{2}{*}{ CCE } & \multicolumn{2}{|c|}{ Consumer confidence } & \multicolumn{2}{|c|}{ Bond yields } \\
\hline & & & $\mathrm{FE}$ & $\mathrm{CCE}$ & $\mathrm{FE}$ & CCE \\
\hline Variables & (1) & $(2)$ & (3) & (4) & (5) & (6) \\
\hline Log unemployment rate & 0.869 & 0.521 & 0.844 & 0.457 & 0.624 & 0.378 \\
\hline (four lags) & {$[0.021]$} & {$[0.028]$} & {$[0.022]$} & [0.029] & {$[0.020]$} & {$[0.033]$} \\
\hline Log expectations & & & -0.118 & -0.142 & 0.473 & 0.123 \\
\hline (four lags) & & & {$[0.024]$} & {$[0.020]$} & {$[0.016]$} & [0.017] \\
\hline \multirow[t]{2}{*}{ EU accession } & 1.212 & 1.043 & 1.199 & 0.906 & 1.141 & 1.035 \\
\hline & [0.041] & [0.067] & {$[0.041]$} & {$[0.086]$} & {$[0.035]$} & {$[0.076]$} \\
\hline \multirow[t]{2}{*}{ Free mobility } & 0.233 & 0.303 & 0.228 & 0.385 & 0.198 & 0.341 \\
\hline & [0.019] & [0.026] & [0.019] & [0.033] & {$[0.016]$} & [0.029] \\
\hline CCE test ( $p$-value) & \multicolumn{2}{|c|}{$48.18(0.00)$} & \multicolumn{2}{|c|}{$34.85(0.00)$} & \multicolumn{2}{|c|}{$24.59(0.00)$} \\
\hline Time dummies & Yes & Yes & Yes & Yes & Yes & Yes \\
\hline Origin seasonal dummies & Yes & Yes & Yes & Yes & Yes & Yes \\
\hline Auxiliary regressors & No & Yes & No & Yes & No & Yes \\
\hline Adjusted $R^{2}$ & 0.974 & 0.994 & 0.974 & 0.995 & 0.981 & 0.995 \\
\hline Countries & 27 & 27 & 27 & 27 & 27 & 27 \\
\hline Observations & 2835 & 2835 & 2835 & 2835 & 2835 & 2835 \\
\hline
\end{tabular}

Notes: migration rates computed using population 15 to 49 ; see also the notes to Table 2.

Source: Authors' elaboration on the data presented in Section 3.

2010, May 2010 to June 2012) and a fourth sub-period of 27 months (July 2012 to September 2014). This greatly reduces the variability that we use for identification, allowing us to better control for the effects of time-varying migration networks at destination and other potential time-varying confounders. This is just an example of many possible subdivisions of the sample: we can also divide it in two, three, five or six sub-periods without any effect on our main CCE estimates. ${ }^{36}$

We present the results with four sub-periods because they still allow us to identify the effects of the policy variables, which happen to be right in the middle of our 2-years-and-2-months divisions: January 2007 for the EU accession of Romania and Bulgaria, May 2011 for the free mobility access of Eastern enlargement workers and January 2014 both for the Croatian EU accession and for the end of free mobility restrictions on Romanians and Bulgarians. In this sense, we identify the policy effects by comparing the evolution of the bilateral migration rate, controlling for the role of expectations in our CCE specification, roughly one year before the change and one year after the change in each of our origin countries.

The results are presented in Table 3. We first remark the decrease in the FE estimate for the association between the unemployment rate at origin and the bilateral migration rate to Germany. It changes from 0.87 in Column (1) of Table 2 to 0.53 in Column (1) of Table 3. This means that this structure of fixed effects is able to eliminate the bias in the estimation of the effect of the unemployment rate on migration rates. The CCE estimate remains robust in the new specification, with a point estimate at 0.50 that cannot be distinguished statistically from the 0.54 estimate in Column (2) of Table 2. However, the policy variables remain biased in the FE specification in Table 3. The coefficient on the free mobility variable remains at 0.24 while the unbiased CCE estimate is 0.31 . The main change corresponds to the EU accession dummy: it goes from 1.21 in Column (1) of Table 2 to 0.79 in Column (1) of Table 3. On the contrary, the CCE is robustly estimated at 1.00 in Column (2) of Table 3, not statistically different from 1.04 in Column (2) of Table 2. Thus, greatly reducing the variability available for identification and the scope for unobservable variables has no effect on the CCE estimates, which

\footnotetext{
$\overline{36}$ Results available from the authors upon request.
}

are consistent under a less restrictive description of the locationdecision problem that potential migrants face, but greatly affects the FE estimates.

In addition, the inclusion of the origin-times-sub-period fixed effects has the virtue of solving the puzzle that the bias on the EU accession dummy was posing in Table 2 . In Table 3 , the bias on the EU accession dummy goes in the expected direction. Once we control for the policy coordination, which is the fact that Romania, Bulgaria and Croatia entered the EU not only with Germany but also with other alternative destinations, we observe that the FE coefficient was downward biased, as predicted by the theory and as it was the case with the free mobility dummy: the estimated effect of EU accession on the bilateral migration rate increases from $e^{0.789}-1 \approx 120 \%$ in Column (1) to $e^{0.999}-1 \approx 172 \%$ in Column (2) of Table 3, with the difference between the two estimated coefficients being significant at conventional confidence levels.

Why does this richer structure of fixed effects get rid of the bias on the unemployment variable, but not on the policy variables? This is just a matter of the strength of the residual correlation of these variables across alternative destinations and dates in time. In this particular application, the origin-sub-period fixed effects happen to absorb the correlation between the current unemployment rate and the expectations about its evolution in the origin and in alternative destinations. In the case of the policy variables, the correlation between the policies of Germany, France, the Netherlands, Italy and many other EU countries is just perfect and biases the FE coefficients even under very demanding specifications. ${ }^{37}$ With respect to Columns (3) to (6) in Table 3, they introduce the two measures of expectations in the same way as Columns (3) to (6) from Table 2. Again, the CCE results do not change except for a slight reduction on the coefficients on expectations while the FE specifications keep the migration policy biases while notably reducing the biases on the rest of variables.

Next, Table 4 repeats exactly the same specifications from Table 2 , but without using population weights. These unweighted results

\footnotetext{
37 One additional comment about column (2) in Table 3 has to do with the test for the convenience of using the CCE estimator; the F-statistic (6.25) is much smaller than the corresponding one in Column (2) of Table 2, which stood at 47.18, reflecting again how the more demanding structure of fixed effects reduces the scope for the role of expectations although the test still clearly rejects the null.
} 
imply that the migration rate from Cyprus to Germany has the same effect on the estimates as the migration rate from Poland to Germany. Nevertheless, the lack of weights should not lead to biased estimates given the large sample size and this is exactly what we observe: none of the CCE coefficients in Table 4 is statistically different from their counterparts in Table 2. In contrast, some of the FE estimates do not appear to be robust to the use of weights and we can observe some large differences between Tables 2 and 4 .

In Table 5, what we change from our benchmark specifications is the definition of our dependent variable. ${ }^{38}$ Rather than calculating the migration rate as a share of the total population of each country of origin in an origin year, which is our proxy for the number of stayers, we divide the inflows by the part of the population that is more likely to be mobile: individuals aged 15 to 49 in each of the origin countries. As in Table 4, the CCE results barely move with respect to Table 2. The reason is that, even with this definition, the variation in the bilateral migration rate is dominated by the changes in the inflows rather than by the changes in the denominator.

\section{Concluding remarks}

Temporary migrations tend to be the rule rather than the exception. However, possibly due to a lack of appropriate data and analytical tools, the micro-foundations of gravity equations for international migration have relied on static models that regard the decision to migrate as permanent. This paper shows that this approach can lead to an incorrect specification of the gravity equation, even if the stochastic component of location-specific utility is not correlated across countries. A dynamic discrete choice model with a wellbehaved stochastic component of location-specific utility implies that the ratio of the probability of opting for two countries at one point in time depends on the future attractiveness and accessibility of all possible locations, unless one assumes either that agents are myopic or that the world is frictionless, i.e., there are no migration costs, thus giving rise to multilateral resistance to migration (Bertoli and Fernández-Huertas Moraga, 2013). If we disregard this dependence, the estimation of the determinants of migration can produce results that are biased in a direction that can be inferred from our micro-foundations.

We take our dynamic migration model to the data with the estimation of the determinants of European migration flows to Germany between January 2006 and September 2014. This period spans some years before and after the Great Recession and its European aftermath and it also covers the accession of Bulgaria, Romania and Croatia to the EU and the introduction of the free movement of workers to Germany for citizens from the countries of the first and second round of the EU's Eastern enlargement. Our results are in line with the predictions of the theory. First, our measure of current economic conditions in origin countries, i.e., the unemployment rate, significantly affects migration flows, but by less than what is obtained with a specification of the gravity equation derived from a static model. Second, this more restrictive model substantially underestimates the effect of migration policies on bilateral flows. Hence, our empirical analysis delivers important insights for policy makers on how institutional changes, namely the Eastern enlargement of the EU and the end of the transitional arrangements, and the formation of expectations about the future in a period of rapid economic changes affect the scale of migration flows. Against the background of optimal currency area theory (Mundell, 1961), the findings of this paper provide also new insights on labor mobility in the Eurozone.

\footnotetext{
38 We also change the population weights accordingly although this does not affect the results; unfortunately, we do not have access to migration inflows by age cohorts.
}

\section{Appendix A. Supplementary data}

Supplementary data to this article can be found online at http:// dx.doi.org/10.1016/j.regsciurbeco.2016.06.012.

\section{References}

Arcidiacono, P., Miller, R.A., 2011. Conditional choice probability estimation of dynamic discrete choice models with unobserved heterogeneity. Econometrica 79 (6), 1823-1867.

Artuç, E., Chaudhuri, S., McLaren, J., 2010. Trade shocks and labor adjustment: a structural empirical approach. Am. Econ. Rev. 100 (3), 1008-1045.

Artuç, E., zden, C, 2014. “Transit Migration: All Roads Lead to the United States. Paper Presented at the Seventh Migration Conference, Oxford.

Bai, J., 2009. Panel data models with interactive fixed effects. Econometrica 77 (4), 1229-1279.

Bandiera, O., Rasul, I., Viarengo, M., 2013. The making of modern America: migratory flows in the age of mass migration. J. Dev. Econ. 102 (1), 23-47.

Beine, M., Bourgeon, P., Bricongne, J.-C., 2013. Aggregate fluctuations and international migration. CESifo Working Paper No. 4379, Munich.

Beine, M., Docquier, F., Özden, Ç., 2011. Diasporas. J. Dev. Econ. 95 (1), 30-41.

Belot, M., Ederveen, S., 2012. Cultural barriers in migration between OECD countries. J. Popul. Econ. 25 (3), 1077-1105.

Belot, M., Hatton, T., 2012. Skill selection and immigration in OECD countries. Scand. J. Econ. 114 (4), 1105-1128.

Bertoli, S., Fernández-Huertas Moraga, J., 2013. Multilateral resistance to migration. J. Dev. Econ. 102, 79-100.

Bertoli, S., Fernández-Huertas Moraga, J., 2015. The size of the cliff at the border. Reg. Sci. Urban Econ. 51, 1-6.

Bertoli, S., Fernández-Huertas Moraga, J., Ortega, F., 2011. Immigration policies and the Ecuadorian exodus. World Bank Econ. Rev. 25 (1), 57-76.

Bertoli, S., Fernández-Huertas Moraga, J., Ortega, F., 2013. Crossing the border: self-selection, earnings and individual migration decisions. J. Dev. Econ. 101 (1), 75-91.

Bijwaard, G.E., Schluter, C., Wahba, J., 2014. The impact of labor market dynamics on the return migration of immigrants. Rev. Econ. Stat. 96 (3), 483-494.

Blanchard, O., Leigh, D., 2013. Growth forecast errors and fiscal multipliers. Am. Econ. Rev. 103 (3), 117-120.

Boeri, T., Brücker, H., 2001. The Impact of Eastern Enlargement on Employment and Labour Markets in the EU Member States Report for the European Commission. European Commission, Brussels.

Brücker, H., Siliverstovs, B., 2006. On the estimation and forecasting of international migration: how relevant is heterogeneity across countries? Empir. Econ. 31 (3), $735-745$.

Canova, F., 2007. Methods for Applied Macroeconomic Research. Princeton University Press, Princeton.

Clark, X., Hatton, T., Williamson, J., 2007. Explaining U.S. immigration, 1971-1998. Rev. Econ. Stat. 89 (2), 359-373.

de Palma, A., Kilani, K., 2007. Invariance of conditional maximum utility. J. Econ. Theory $132(1), 137-146$

Dustmann, C., Görlach, J.-S., 2015. Selective out-migration and the estimation of immigrants' earnings profiles. In: Chiswick, B.R., Miller, P.W. (Eds.), Handbook of the Economics of International Migration, Vol. 1 pp. 489-533 North-Holland.

Eberhardt, M., Helmers, C., Strauss, H., 2013. Do spillovers matter when estimating private returns to R\&D? Rev. Econ. Stat. 45 (2), 436-448.

European Central Bank, 2015. Long-term interest rate statistics for EU member states. Accessed on May 14, 2015 https://www.ecb.europa.eu/stats/money/long/html/ index.en.html

European Commission, 2015. Business and consumer confidence. Accessed on April 8, 2015 http://ec.europa.eu/economy_finance/db_indicators/surveys/time_ series/index_en.htm

Eurostat, 2015. Government bond yields, 10 years maturity, monthly data. Accessed on April, 82015 http://appsso.eurostat.ec.europa.eu/nui

Eurostat, 2015. Harmonised unemployment rate. Accessed on April 8, $2015 \mathrm{http}$ ://epp. eurostat.ec.europa.eu

Eurostat, 2015. Population. Accessed on May 28, 2015 http://epp.eurostat.ec.europa. eu

Fertig, M., 2001. The Economic Impact of EU-enlargement: assessing the migration potential. Empir. Econ. 26, 707-720.

Flaig, G., 2001. Die abschätzung der Migrationspotenziale der osteuropäischen EU beitrittsländer. Appl. Econ. Q. 52 (Supplement), 55-76.

Galí, J., 2015. Hysteresis and the European unemployment problem revisited. NBER Working Paper No. 21430.

Grogger, J., Hanson, G.H., 2011. Income maximization and the selection and sorting of international migrants. J. Dev. Econ. 95 (1), 42-57.

Hanson, G.H., McIntosh, C., 2012. Birth rates and border crossings: Latin American migration to the US, Canada, Spain and the UK. Econ. J. 122 (561), 707-726.

Keane, M.P., Wolpin, K.I., 1997. The career decisions of young men. J. Polit. Econ. 105 (3), 473-522.

Kennan, J., Walker, J.R., 2011. The effect of expected income on individual migration decisions. Econometrica 79 (1), 211-251.

Lee, D., 2005. An estimable dynamic general equilibrium model of work, schooling and occupational choice. Int. Econ. Rev. 46 (1), 1-34. 
Lewer, J.J., van den Berg, H., 2008. A gravity model of immigration. Econ. Lett. 99 (1), $164-167$.

Mayda, A.M., 2010. International migration: a panel data analysis of the determinants of bilateral flows. J. Popul. Econ. 23 (4), 1249-1274.

McFadden, D., 1974. Conditional logit analysis of qualitative choice behavior. In: Zarembka, P. (Ed.), Frontier in Econometrics Academic Press, New York, pp. 105-142

McFadden, D., 1978. Modeling the choice of residential location. In: Karlqvist, A. (Ed.), Spatial interaction theory and planning models North-Holland, Amsterdam, pp. 75-96

Mundell, R.A., 1961. A theory of optimum currency areas. Am. Econ. Rev. 51 (4), 657-665.

OECD, 2014. International Migration Outlook. OECD, Paris.

Ortega, F., Peri, G., 2013. The role of income and immigration policies in attracting international migrants. Migr. Stud. 1 (1), 47-74.

Pedersen, P.J., Pytlikova, M., Smith, N., 2008. Selection and network effects-migration flows into countries 1990-2000. Eur. Econ. Rev. 52 (7), 1160-1186.

Pesaran, M.H., 2006. Estimation and inference in large heterogeneous panels multifactor error structure. Econometrica 74 (4), 967-1012.
Pesaran, M.H., Tosetti, E., 2011. Large panels with common factors and spatial correlation. J. Econ. 161 (2), 182-202.

Pessino, C., 1991. Sequential migration theory and evidence from Peru. J. Dev. Econ. 36 (1), 55-87.

Schneider, J., 2012. Practical measures for reducing irregular migration. Federal Office for Migration and Refugees Working Paper No. 41.

Sinn, H.-W., Werding, M., Münz, S., Düll, N., Hoffmann, H., 2001. EU Erweiterung Und Arbeitskräftemigration. ifo Institute, Munich.

Sjaastad, L.A., 1962. The costs and returns of human migration. J. Polit. Econ. 70 (1), 80-93.

Small, K.A., Rosen, H.S., 1981. Applied welfare economics with discrete choice models. Econometrica 49 (1), 105-130.

Bundesamt, Statistisches, 2015. Bevoelkerung Und Erwerbstaetigkeit: Wanderungen 2006-2014. Statistisches Bundesamt, special data provision, Wiesbaden.

Vogel, D., Assner, M., 2011. Umfang, Entwicklung Und Struktur Der Irregulären Bevölkerung in Deutschland, Mimeo. Bundesamt für Migration und Flüchtlinge, Hamburg and Nuremberg.

Vogler, M., Rotte, R., 2000. The effects of development on migration: theoretical and new empirical evidence. J. Popul. Econ. 13 (3), 485-508. 